\title{
Genetic Engineering and Its Application in Animal Breeding: Review
}

\author{
Mebrate Getabalew ${ }^{1}$, Tewodros Alemneh ${ }^{2 *}$ and Derbie Zewdie ${ }^{3}$ \\ ${ }^{1}$ College of Agricultural and Natural Resources Science, Department of Animal Science, Debre Berhan University, Ethiopia \\ ${ }^{2}$ Woreta City Office of Agriculture and Environmental Protection, South Gondar Zone, Amhara Regional State, Ethiopia \\ ${ }^{3}$ Ankober Woreda Agricultural and Developmental Office, North Showa Zone, Amhara Regional State, Ethiopia
}

*Corresponding author: Tewodros Alemneh, Woreta City Office of Agriculture and Environmental Protection, South Gondar Zone, Amhara Regional State, Ethiopia; Tel. 2519204998 20; Email: tedyshow@gmail.com

Received Date: August 23, 2020

Published Date: October 06, 2020

\begin{abstract}
Genetic engineering, also called genetic modification, is the direct manipulation of an organism's genome using biotechnology. Genetic engineering alters the genetic makeup of an organism using techniques that remove heritable material, or that introduce DNA prepared outside the organism either directly into the host or into a cell that is then fused or hybridized with the host. This involves using recombinant nucleic acid (DNA or RNA) techniques to form new combinations of heritable genetic material, followed by the incorporation of that material either indirectly through a vector system or directly through micro-injection, macro-injection and micro-encapsulation techniques. Genetic improvement has played important roles in improving the desired traits' efficiency of cattle, sheep, pigs and poultry. It has advanced applications in livestock breeding including increase animal production and productivity (meat, milk, wool), improve disease resistance, and biomedical applications (vaccine production). In livestock, knowledge of effects of specific genes and gene combinations on important traits could lead to their enhanced control to create new, more useful populations. Hence, the objectives of this review were to overview on the genetic engineering and its application in animal breeding, and to highlight the general concepts, techniques, types, importance and limitations of genetic engineering application in animal breeding.
\end{abstract}

Keywords: DNA; Genetic engineering; Genetic improvement; Animals; Breeding; Production

\section{Introduction}

Genetic engineering is the name of a group of techniques used for direct genetic modification of organisms or population of organisms using recombination of DNA. These procedures are of use to identify, replicate, modify and transfer the genetic material of cells, tissues, or complete organisms [1,2]. Genetic engineering in animal production has a growing number of practical benefits, such as in the production of transgenic animals resist to disease, increasing productivity of animals, in the treatment of genetic disorders and in the production of vaccines. This technology will supply various applications in biomedicine that are rather impossible without it [3]. Away from economic constraints, there are concerns of well-being and ethics as introduction of genes from one organism to another may create alteration of the natural genetic balance and lead into unwanted consequences.

Although the existing limitations, the application of this radical technology to increase livestock productivity could be not satisfying in the Ethiopian context. The technology should also be sophisticated in a way to minimize well-being and ethical concerns [4]. Different genes are responsible for the various characteristics and properties of a living organism. To change part of an organism's genome to create some desired or beneficial trait we use genetic engineering [5]. Now it is possible to directly alter a genome and 
insert or remove a chunk of DNA to create something beneficial the rapid developments in the field of genetic engineering have given a new movement to biotechnology. This introduces the possibility of dress making organisms to optimize the production of established or novel metabolites of commercial importance and of transferring genetic material from one organism to another [3]. In order to achieve potential benefits of genetic engineering the only need is to develop perfect tools and techniques. Once it has been perfected, all the problems associated with food production can be solved, the world environment can be restored, and human health and lifestyle will be improved beyond imagination. No doubt that there are almost no limits to what can be achieved through responsible genetic engineering [6]. For that reason, the general objective of this review focuses on the application of genetic engineering to animals for genetic improvement of animal breeding, including a description of the methods, their potential and current uses, and ethical issues.

\section{Genetic Engineering: Concepts}

Genetic engineering is the name of a group of techniques used to identify, replicate, modify and transfer the genetic material of cells, tissues or complete organisms. This biotechnology of gene therapy, scientists are making efforts at curing genetic diseases by attempting to replace defective genes with the correct version and also used to produce more effective and efficient vaccines, therapeutic antibodies, antibiotics and other pharmaceuticals [7].

There are more than 370 drug products and vaccines obtained through biotechnology currently in clinical trials, targeting more than 200 diseases including various cancers, Alzheimer's disease, heart disease, diabetes, multiple sclerosis and arthritis [8]. Animal breeding operates through the selection of genetically superior animals as parents for subsequent generations. So far artificial selection could therefore only be applied to traits which are "naturally" exhibiting genetic variation in the selected populations, i.e. traits characterized by some degree of "heritability" [9].

The rate of genetic progress or of response to selection is a function of the accuracy of selection, i.e. the precision in the identification of genetically superior animals; the generation interval, the shorter the generation interval, the faster the genetic progress; the selection intensity, i.e. the more the future parental individuals deviate from the average breeding value of their contemporaries, the higher the genetic improvement they will cause. Biotechnology is being applied to enhance genetic progress through these four factors: increase genetic variation (or the molecular substrate of breeding programmes), increase the accuracy of selection, and reduce the generation interval and to increase the selection intensity. Three major topics can be distinguished in the area of biotechnology applied to the genetic improvement of livestock: reproductive technologies, livestock genomics and marker assisted selection (MAS), and livestock transgenics [3].

\section{Types of Genetic Engineering Applications in Animal Breeding}

Genetic engineering applications in animal breeding includes a description of the methods, their potential and current uses and ethical issues. Genetic engineering is the name of a group of techniques used to identify, replicate, modify and transfer the genetic material of cells, tissues or complete organisms [10]. The important applications of genetic engineering in animal breeding are as follows:

\section{Marker-assisted Selection (MAS)}

The objective of this technology is to increase disease resistance, productivity and product quality in economically important animals by adding information of DNA markers to phenotypes and genealogies for selection decisions [10].

\section{Transgenesis}

the direct transfer of specific genes/alleles between individuals, species, or even Kingdoms, in order to change their phenotypic expression in the recipients. Compared to the 'traditional' improvement techniques based on phenotypic information only, these gene-by gene techniques allow theoretically a more complete management of animal genomes for animal breeding [10].

The MAS method is fruitful for traits with a simple genetic determinism but delivers unsatisfactory outcomes in many more complex conditions. The two key causes for this low productivity were the limited part of the genetic variance and also the low association between markers and QTL at population level. Another limitation of MAS is the expensive cast of genotyping of selection candidates, due to the benefits of MAS in commercial breeding programs [11].

\section{Genomic Selection in Ruminants}

The objective of dense arrays for detection of SNPs has different implications according to the species of interest. In dairy cattle, it has been used to discover markers that will improve the reliability of traits associated with milk production, cow health, and cow conformation. Australia is the leading country in identifying genomic regions associated with milk production [12] and several studies have also been completed in the United States, Canada and some other countries [5,13]. Application of genomic estimation has caused significant changes in dairy cattle breeding; the reliability of genomic prediction in dairy cattle exceeds 0.8 for production traits and 0.7 for fertility and other traits $[13,14]$

The genotyping of young bull increased the genetic gain and also significantly lowered the cost compared to the genotyping of heifer calves. The lower cost of genomic selection compared to traditional methods has made an incredible impact on the development of dairy industry genomic selection could principally benefit more the beef cattle industry paralleled to dairy because beef cattle have long generation interval. Snags of saving phenotype 
data of satisfactory value and size hamper tradition methods for conventional evaluation; consequently, genomic selection has the efficiency to significantly improve the genetic gain by increasing selection reliability at an early age [15].

\section{Techniques of Genetic Engineering}

\section{Exogenous pronuclear DNA Micro-injection in zygotes}

Micro-injection is the first successful approach for the creation of transgenic animals based on the injection of a foreign DNA construct into a fertilized oocyte [5]. The construct integrates randomly into the host oocyte genome, subsequently the zygote continues embryonic development and the embryo is transferred to a foster mother and eventually develops to a transgenic animal [16]. However, this method has strong limitations: on average, less than $1 \%$ of embryos injected and $10 \%$ of animals born are transgenic, genes can only be added, not replaced or deleted, and multiple copies of the transgene are inserted at random, hindering the correct regulation of gene expression and possibly interfering with endogenous gene function. This requires large amounts of oocytes to be injected, as the overall efficiency of the process is very low [17].

\section{Injection of genetically modified embryonic stem (ES) cells into blastocysts}

Embryonic stem cells are derived from embryos at a very early stage (the blastula) and possess the important characteristics of pluripotency. Pluripotency is the ability of these cells to differentiate to any of the cell types and tissues found in the adult organism [9]. Embryonic stem cells can be grown in culture for many passages and can be subjected to transformation with transgene constructs, resulting in modifications of their genome. The constructs used not only permit the selection of successfully transformed cells, but also allow gene targeting to be accomplished. Thus, genes can be specifically introduced, replaced or deleted (so-called knock-ins and knockouts) [18]. Injection of genetically modified embryonic stem (ES) cells into blastocysts, mainly through the feature of gene targeting, allows a broad variety of genetic modifications to be introduced. For many years, several laboratories worldwide have tried to produce ES cells from farm animals, and although some succe has been claimed, no robust and reproducible method has been published. Indeed, even in mice the production of ES cells is a costly and labor-intensive technology [19].

\section{Retrovirus mediated gene transfer}

Transgenes is may also be accomplished by employing virus derived vectors; namely, vectors based on the retrovirus-class of lenti viruses [20]. Genes that are essential for viral replication are deleted from the viral genome, maintaining only the capacity for integration of the viral genome into the host genome. The parts of the viral genes can replaced by the transgene of interest, then viruses carrying the modified gene are produced in-vitro and subsequently injected into the perivitelline space of the zygote, resulting in infection of the zygote and integration of the viral genome into the host genome [5]. Transgenesis rates reaching up to $100 \%$ of injected embryos have been described. Major drawbacks of this method are a limited transgene size and random transgene integration. Random and possibly multiple transgene integration may lead to position effects, disturbance of the host genome and dose effects, as is the case with pronuclear injection. Solving these problems holds great promise for the further development and application of lenti viral vectors [21].

\section{Uses of Animal Genetic Engineering}

\section{Increase animal disease resistance}

Genetic engineering of agricultural animals has the potential to improve disease resistance by introducing specific genes into livestock [22]. Identification of single genes in the major histo compatibility complex (MHC), which influence the immune response, was instrumental in the recognition of the genetic basis of disease resistance/susceptibility [17].

Animal biotechnology offers a number of approaches to fight diseases in animals. Firstly, through genetic selection, livestock producers can select for certain traits that are associated with disease resistance and populations of animals that are less vulnerable to diseases could be developed. Secondly, through genetic engineering, breeders can integrate disease resistance genes from new sources, allowing for improved animal health [23]. Disease resistance benefits not only livestock producers and their animals, but consumers also benefit as a result of safer animal products in the market, and a reduction in the incidence of human-transmissible diseases such as avian influenza [24]. Increased disease resistance can be achieved by introducing resistance-conferring gene constructs into animals or by depleting a susceptibility gene or locus from the animal. Hence, gain of function (additive) as well as loss of function (deletive, knock-out) gene transfer experiments can be used. Gene transfer experiments are often hampered by the lack of identified major genes or loci responsible for resistance traits [23,25].

\section{Increase meat and milk production}

The application of genetic engineering to increase milk and meat is a "value-added" opportunity in animal agriculture as it increases the concentration of existing proteins or producing entirely new proteins $[16,23]$. Genetic engineering is important to increase milk and meat production of animals for the ever increasing human population in global. The production of human lysozyme in milk of transgenic mice also increased the an-timicrobial properties of the milk, which in cows could reduce infections in the mammary gland and perhaps eliminate undesirable pathogens in the gut of humans who consume the milk. Cattle are known as the best animals for producing large amounts of milk and/or meat and are regarded as a valuable protein resource [26]. Evidences showed that the presence of 10 to $20 \%$ altered casein in milk produced by a transgenic cow could increase proteolysis and thereby promote the faster ripening of cheese. Results of experiments with transgenic mice illustrated 
the positive effects of adding genes such as the casein gene or human lysozyme gene [23] to the milk protein system [23,27]. The effects of genes encoding growth hormone- releasing factor (GRF) or insulin-like growth factor I (IGF- I) were reported in growth studies in mice and sheep [23]. In pigs, there are evidences of transgene effects that reduced body fat and increased muscle fiber diameter by increasing IGF-I levels and growth hormone with no serious pathological side effects $[23,28]$.

\section{Improve wool production}

The control of the quality, color, yield and ease of harvest of hair, wool and fiber for fabric and yarn production has been an area of focus for genetic engineering in livestock [29]. The manipulation of the quality, length, fineness and crimp of the wool and hair fiber from sheep and goats has been examined using transgenic methods [16]. The objectives aimed to improve sheep for wool production and to modify the properties of the fiber. Because cystein seems to be the limiting amino acid for wool synthesis, the approach is to increase its production through transfer of cystein biosynthesis from bacterial genes to sheep genome [23]. Transgenic methods also allow improvements to fiber elasticity, surface and strength. Decreasing the surface interactions between fibers could decrease shrinkage of garments made from such fibers [30].

\section{Vaccine production}

Vaccination generally involves injecting weak live, killed, or inactivated forms of viruses or their toxins into the animal being immunized [31]. Most conventional vaccines are killed microorganisms, inactivated bacterial toxins or live attenuated organisms. However, because the immune system acts only on a few protective immunogens, most molecular components of killed vaccines are redundant and or can cause adverse effects. To reduce these effects, nowadays, new technologies offer alternatives to classical vaccines [32]. Most vaccines are now genetically modified. Genetically, engineered viruses are being developed that can still confer immunity, but lack the infectious sequences [31].

\section{Limitations of Genetic Engineering}

\section{Religious, cultural and ethical Issues}

The current and potential impact of rapid developments in biotechnology to effect new innovations in medicine and drug development, as well as such diverse areas as crime detection, agriculture, pollution control and industrial processes, brings into question how these techniques can be used constructively without damaging the cornerstones of religious ethics like respect for human life [33]. Revolutionary innovations in genetic engineering, the decoding of the human genome now make it possible for vegetables in our food chain to bear animal transgenes [34].

\section{Economic constraints}

The requirement of adequate infrastructure is a critical factor for the establishment of biotechnology companies. While research and development budgets for biotechnology research are only beginning to pick up in developing countries, start-up funding for biotechnology companies is still very rare to come by financing early stages of business development could be achieved through seed funding, easier access to loans and venture funds [35].

\section{Antibiotic resistance}

The major concern with the use of antibiotic resistance marker genes is that they will diminish the efficacy of antibiotics in humans and animals [36]. The large presence of antibiotic resistance genes in the environment and soil, as well in the food eaten by animals and humans, could pass the trait of antibiotic resistance rapidly and widely. This can occur through a transfer of antibiotic resistance marker genes to bacteria in the guts of animals or humans, or to bacteria in the environment. Many bacteria have the ability to pick up genes from their surroundings and to pass these genes on to other species of bacteria including antibiotic resistance marker genes. Such genes might eventually find their way into diseasecausing bacteria, resulting in antibiotic resistance and therefore making treatment more difficult [7].

\section{Conclusion}

Genetic engineering in animal production has a growing number of practical benefits, such as in the production of transgenic animals resist to disease, increasing productivity of animals, in the treatment of genetic disorders and in the production of vaccines. This technology will provide various applications in biomedicine that are rather unthinkable without it. Apart from economic constraints, there are concerns of well-being and ethics as introduction of genes from one organism to another which may create alteration of the natural genetic balance and leads into undesirable consequences.

\section{Acknowledgement}

Authors' would like to say thanks to the almighty God and his Mother, Saint Merry, for their devotion and support to complete the overall tasks with the aid of their intervention.

\section{Conflict of Interests}

Authors' declare no conflict of interests.

\section{References}

1. Izquierdo, Marta (2001) Genetic engineering transference engineering. $2^{\text {nd }}$ ed. Madrid, Edicione Pirámide, pp. 344

2. Karp, Gerald (2008) Cell and Molecular Biology: concepts and Experiments. $3^{\text {rd }}$ ed. New York, Willey, 785 p. ISBN04-714-6580.

3. Blasco A (2007) The role of genetic engineering in livestock production Livestock Science 113(2-3): 191-201.

4. Frewer L van der Lans I, Fischer A, Reinders M, Menozzi D, et al. (2013) Public Perceptions of Agri-food Applications of Genetic Modification A Systematic Review and Meta-Analysis. Trends in Food Science and Technology 30(2): 142-152

5. Jiang L (2010) Genome wide association studies for milk production traits in Chinese Holstein PLoS One 5(10): e13661. 
6. Smith M, Asche F, Guttormsen A, Wiener J (2010) Genetically modified salmon and full impact assessment. Science 330: 1052-1053.

7. Sullivan E, Pommer J, Robl J (2008) Commercializing genetically engineered animal biomedical products. Reprod Fertil Dev 20: 61-65.

8. Mora C, Menozzi D, Kleter G, lusine H, Ara M, et al. (2012) Factors Acting the Adoption of Genetically Modifed Animals in the Food and Pharmaceutical Chains, Bio-based and Applied Economics 1(3): 313 329.

9. Conrad G, Harold C (2009) Acceptable Genes. Religious, Traditional and Genetically Modified Foods State University of New York Press, Albany, pp 135-140.

10. Ibtisham F, Zhang L, Xiao M, Lilong A, Muhammad B, et al. (2017) Genomic selection and its application in animal breeding. 47(3): 301310.

11. Boichard D (2016) Genomic selection in domestic animals: Principles, applications and perspectives compte rendus biologies 339(7-8): 274 277.

12. Bolormaa S (2010) Multivariate analysis of a genome wide association study in dairy cattle. Journal of dairy science 93(8): 3818-3833.

13. Wiggans G, VanRaden P, Cooper T (2011) The genomic evaluation system in the United States: Past, present, future. Journal of Dairy Science 94(6): 3202-3211.

14. Lund M (2011) A common reference population from four European Holstein populations increases reliability of genomic predictions. Genetics Selection Evolution evolution 43(1): 43.

15. Jonas E, Koning D (2015) Genomic selection needs to be carefully assessed to meet specific requirements in livestock breeding programs. Frontiers in Genetics 6: 49.

16. Scott G, Mattew B (2011) Genetically engineered animals and public health. Compelling Benefits for Health Care, Nutrition, the Environment, and Animal Welfare 22-30.

17. Ayana E, Fentahun G, Gizachew, Negash A, Mitku F, et al. (2017) Review on Applications of Genetic Engineering and Cloning in Farm animal 4(1)

18. Denning C, Priddle H (2003) New frontiers in gene targeting and cloning success, application and challenges in domestic animals and human embryonic stem cells. Reproduction 126(1): 1-11.

19. Melo E, Canavessi A, Franco M, Rumpf R (2007) Animal trangenesis: state of the art and applications. J Appl Genet 48(1): 47-61.

20. Whitelaw C, Lillico S, King T (2008) Production of transgenic farm animals by viral vector-mediated gene transfer. Reprod Domest 2:355358.

21. Park F (2007) Lent viral vectors: are they the future of animal Transgenesis Physiology Genomics 31(2): 159-173. population. PloS one 5(10): e13661.
22. Nyerhovwo J (2004) Fostering biotechnology entrepreneurship in developing countries. Afr J Biotechnol 3: 291-300.

23. Asaye M, Biyazen H, Girma M (2014) Genetic engineering in animal production: Applications and prospects. Biochem Biotechnol Res 2(2): $12-22$.

24. Alison VE, Davis UC (2009) Potential effects of biotechnology on animal health and well-being. Applications of Animal Biotechnology in Animal Health, Department of Animal Science, University of California, California 1-5.

25. Muller M, Brem G (1998) Transgenic approaches to the increase of disease resistance in farm animals. Revue Scientifique et TechniqueOffice International Des Epizooties 17: 365-373.

26. 26.Yum, S, Youn, K, Choi, W (2018) Development of genome engineering technologies in cattle: from random to specific. J Animal Sci Biotechnol 9.

27. James DM, Gary BA (2000) Genetic engineering and cloning may improve milk, livestock production. California Agric 54: 62-63.

28. Hugon HM (2006) Genetic engineering applications in animal breeding. Elect J Biotechnol, 9: 158-162.

29. Hollis D, Chapman R, Panaretto B, Moore G (2004) Morphological changes in the skin and wool fibers of Merino sheep infused with mouse epidermal growth factor. Aust J BiolSci 36(4): 419-34.

30.Vàzquez-Salat N, Salter B, Smets G, Houdebine L (2012) The current state of GMO governance: Are we ready for GM animals? Biotechnology Advances 30(6): 1336-1343.

31. LibreTexts Libraries (LTL) (2019) Genetically Engineered Vaccines.

32. Sussan E, and Asa M (1998) The Merck veterinary manual. $8^{\text {th }}$ Edition. Merck and Co. Inc. W hite House station, New York, Pp 187-1880.

33. Curran G, Koszarycz Y (2004) Genetic engineering: Creating an ethical framework. Australian Journal of Theology 2: 1-6.

34. Mega EA, Shoemaker CF, Rowe JD, BonDurant RH, Anderson GB, et al. (2006) Production and processing of milk from transgenic goats expressing human lysozyme in the mammary gland. J Dairy Sci 89(2): 518-524.

35. Areal F, Riesgo L, Gómez-Barbero M, Rodríguez-Cerezo E (2012) Consequence of a coexistence policy on the adoption of GMHT crops in the European Union. Food Policy 37(4): 401-411.

36. Prakash C (2002) Look Mom! No Antibiotic Resistance Marker Genes.

37. Murray J, Mohamad-Fauzi N, Cooper C, Maga E (2010) Current status of transgenic animal research for human health applications. Acta Scientiae Veterinariae 38(Suppl 2): 627-632. 